\title{
Ego and id
}

Cite as: CMAJ 2019 June 3;191:E615-6. doi: 10.1503/cmaj.181581

CMAJ Podcasts: audio reading at https://soundcloud.com/cmajpodcasts/181581-enc

t's a very strange sensation for your body to feel foreign.

For me, it began innocuously enough, a tickle on the plantar aspect of my left foot, between my fourth and fifth digits. An unexceptional patch of skin, normally unblemished. Soft, unyielding, clear, ignored - had I ever paid much attention to my feet?

A third-year medical student, I dismissed the tickle, the unpleasant desire to scratch that hadn't existed before. I continued to function in the world that mattered most: a reality fabricated of scripted exams and sterile corridors, of methodologically composed diagrams and industrial lights, of brightly calculated mornings magnified by coffee. The hyper-real routine enforced a sense of self-imposed discipline, and it cocooned me; if I abided by the rules of my simulation, I would glean its rewards.

So when, exactly, my foot had erupted, I can't truthfully say.

The sensation in my hands alarmed me first. It began as an otherworldly simmer in my palms, a slow, steady smouldering with no explanation as to its cause. The invisibility, the sensation of that which could not be named, frightened me most; it was the unimaginable terror derived from a creature in the dark. I remembered my foot - the tickle that had progressed to itch, the itch that had progressed to nuisance - and yanked off my socks. The recognition of pathology frightened me, and made me ashamed: there, the previously perfect interdigital space was now occupied by grotesque, inflamed, hyperkeratotic scale. This is not my foot.

I received my first diagnosis in a walkin clinic, under a poster animatedly describing the digestive system.

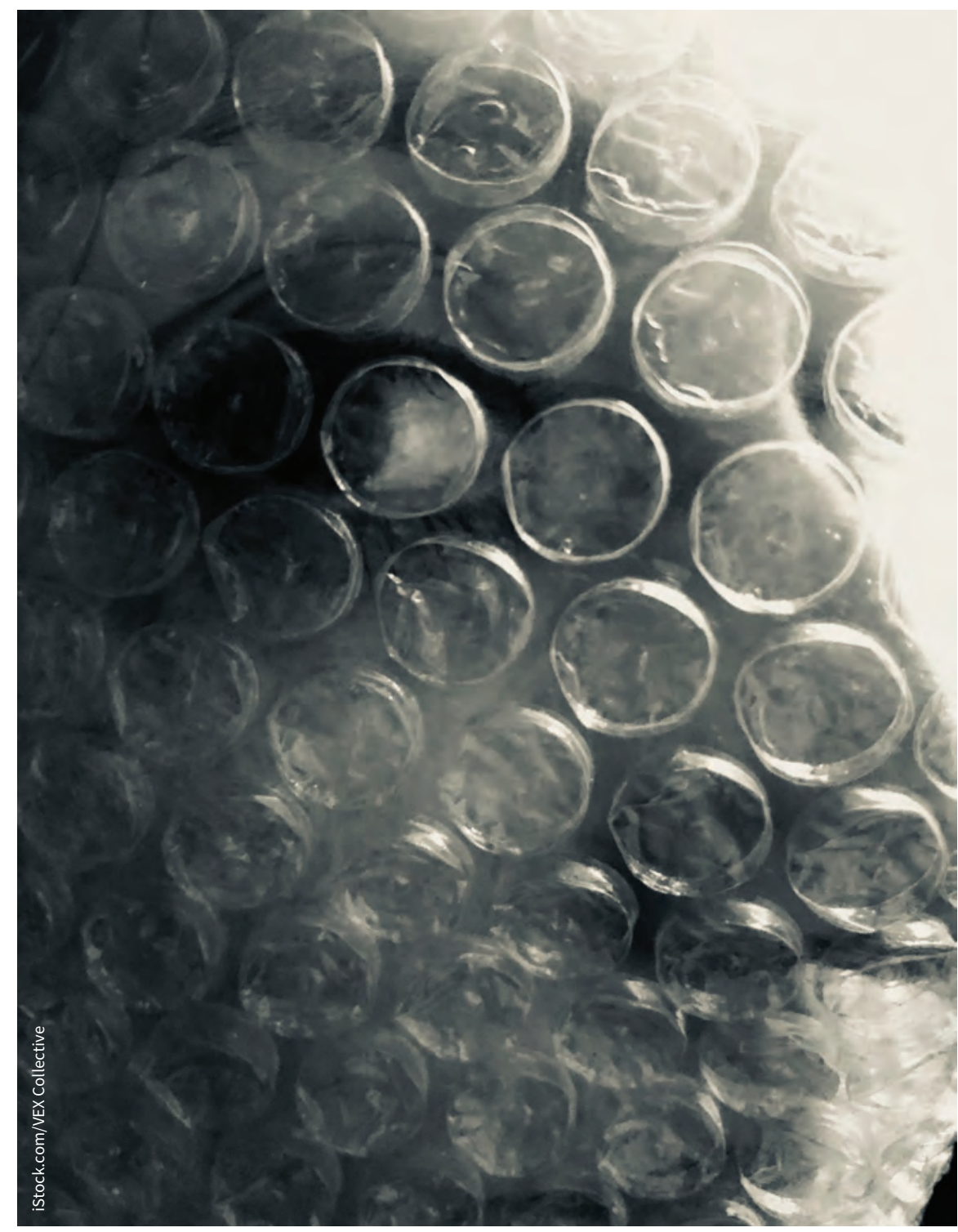

Diagnosis: tinea pedis, or athlete's foot. Treatment: topical antifungal.

"But what," I asked, my voice a plea, "is making my hands burn?"

With diligence and care, my hands were examined, my inconspicuous palms turned to the sky.
"I'm not sure. I don't see anything try the topical antifungal for your feet."

This, of course, seemed reasonable. How do you treat that which you cannot see? I felt irrational, I felt absurd. I narrated the situation to an invisible audience, my personhood reduced to an 
Animal Planet special. The hypochondriac medical student, entrenched in a form of situational ventriloquism.

Then, unexpectedly, my limbs erupted.

Supernatural, fluid-filled blisters made home of my body. They covered the sides of my fingers, disfiguring them. They wrapped the sides of my feet, curiously translucent. They itched intensely, ruthlessly, unforgivingly, unforgivably. At some point, my entire person became overtaken by prickliness - my arms, my legs, my torso. My skin no longer felt familiar; I was unravelling at the seams. This is not my body.

In response to uncharted territory, my imagination ignited. Terrifying events transpired within my anatomy, their narrative outside the force of my discipline. I pictured fungal spores migrating through my bloodstream, setting up shop at the dermal level and replicating. I fretted that, while on my pediatrics rotation, I had contracted scabies. Lastly, and most disquietingly, I agonized that my condition hadn't been documented. It was all too real; none of it was real enough. This is not my world.

Rejecting my admonishing mind, my body underwent fractious rebellion and there was no way for me to govern its anarchy.

I received my first referral seated on a chilly gurney, goosebumps on my exposed body, a war raving inside me, a polite smile plastered on my face.

There were now strange beings to be seen on my hands and feet: tiny, bubblelike intruders had created colonies that tracked my fingers, my palms, the sides of my feet, my soles. I was bubble wrap without the pop.

"What is it?" I asked the attentive emergency department physician.

"Hmm, I'm not sure," he replied, perplexed, "but go to an emergency dermatology clinic."
My second diagnosis was received in a beautiful brick-lain office, where my deformed feet and pockmarked body provided laughable contrast to the pristine surroundings. Look at me. Don't look at me.

"You've had a severe id reaction," । was told almost immediately.

An entire revolt, an entire insurgency, reduced to one syllable.

Amid explanations of mechanisms of hypersensitivity, my brain shut off: it focused on the labelling of disease, the name given to the previously unnameable. I rolled the word around in my mouth. Id.

I looked up case reports beautifully illustrated with hideous coloured photos of others' suffering. I read everything I could get hold of; it was the method of coping I knew best. The descriptions were more or less similar. "An acute, intensely pruritic, symmetric papulovesicular reaction that involves the forearms, thighs, legs, trunk, face, hands, neck and feet."

How funny that it should be called "id," I mused. Here was a name for my mind-body disconnect; here was a name for my mutiny. I Google-Imaged id reactions, finding perverse pleasure in locating other prisoners of war. I am not alone.

My imagination involuted, replaced by cold, hard science, and a sudden resurgence of control. I could name the intruder. I could look up photos; I could read reports. I could that accept that salvation took the form of tiny, sour-tasting tablets that must be counted individually in one's palm. So this is what prednisone tastes like.

Six months after its onset, the id dissipated for good. The dyshidrotic papules occupying my hands and feet left, leaving faint, hyperpigmented traces where they'd once tormented me. The intense eczema on my arms, legs and torso faded, soothed with daily application of a steroid. The tinea receded, disappearing in the order it had appeared, leaving gossamerlike imprints in its wake.

I laugh when I tell the story now. Had I only treated a simple case of athlete's foot earlier! Silly me! I negate the ways in which I broke - the ways in which the otherworldly bubbles on my feet grew so large and painful they had to be lanced. The ways in which I limped for a week. The ways in which I cried in hospital bathrooms in the middle of the days, pain and itch closely intertwined. Ha, ha! Silly me! I hide behind the cloak of metaphor - of aliens and war, of ego and id, of perceived control and simulacrum.

Why do I do this?

I think - I think - that I want you to know the ways in which I'm hiding. I want to know if you are hiding, too. If you see me uncloaked - a student of science, imagination unchecked, anxieties rampant, play-pretending to be Strong and Smart and Unbreakable - will I get to see you, too?

As medical professionals, we rarely speak about our own ailments. We hide; perhaps not behind metaphor, but behind sterile language - best applied to others, never to ourselves. Why do I share this story now - years after its occurrence? I share it because I think our narrative arcs aren't always about the stories we do tell, but those we don't those we leave carefully concealed. Those that, slowly, thankfully, can emerge from the brickwork. Those that make us what we are, beneath the facades and fluorescent lights and fears and fancies: Strong and Smart and Perfectly Breakable.

\section{Sumedha Arya MD}

Department of Medicine, University of Toronto, Toronto, Ont.

This article has been peer reviewed. 